\title{
BJET Editorial for the 50th Anniversary Volume in 2019: Looking back, reaching forward
}

\author{
Sara Hennessy, Manolis Mavrikis, Carina Girvan, Sara Price and Niall Winters \\ Introduction
}

The Editors are thrilled to introduce the 50th Anniversary volume of the British Journal of Educational Technology (BJET). This momentous milestone has spurred us to share with the readership our pride and sense of responsibility for editing one of the top journals in the field. We are, of course, supported by the dedicated International Advisory Board, Editorial Board, reviewers, authors and readers who have made this possible over the years, plus the British Educational Research Association (BERA) and the publisher - Wiley - so we extend a huge thank you to you all. This includes all of the previous Editors, especially Nick Rushby, who stepped down in January 2016 after maintaining and developing the journal's strong reputation in the field during his 23 years of dedicated service. BJET has gone from strength to strength throughout its long history of publishing world-class research reports and reviews.

This first, bumper issue has some special, featured research reviews and each subsequent issue in 2019 will likewise contain some celebratory sections and editorials by guest editors. These are intended to take stock of the field and its progress to date, and to look forward to what may be in store in the future and what the community would like to see. In this editorial, we would like to take the opportunity to look back over the past 50 years and explore the upcoming future.

\section{Looking Back}

The offer of a review of BJET content over the past 5 decades, our first feature in this issue (by Bond, Zawacki-Richter and Nichols), provided a unique opportunity for us to reflect on 50 years of the field in general. BJET, initially known as the Journal of Educational Technology, started out in a humble fashion, with three small issues a year. The first volume in 1970 edited by Norman Mackenzie of University of Sussex contained articles with titles such as "Audiovisual resources in Sussex schools", "Programmed learning in Africa 1963-1969" and "University TV research at Leeds". The image of the first issue's cover in Figure 1 shows that it focused on audiovisual technologies. Educational technology was framed as audiovisual equipment including slide projectors, film, radio and television. While some of these may now be obsolete, the reflections in that volume still seem applicable to today's field even if the technology has changed. The initial statement about the journal's focus remains remarkably contemporary:

[Insert quite from BJET Editors, 1970a, p. 5]

[Insert image] 
Fig. 1. Cover of inaugural issue of BJET (initially entitled Journal of Educational Technology), January 1970

The inclusion of 'curriculum development and course design' in the original journal mission statement is interesting in light of comments on the Bond et al. review by one longstanding BJET referee: that the papers published in the 1980s and 1990s did not feature the massive shift in curricula occasioned by the advent of technology, especially the internet, during that era. This changing emphasis towards higher order cognitive skills could have benefited hugely from a pedagogy for technology-mediated learning to facilitate development of these skills. Yet the scope of BJET articles during this period largely did not engage with this pressing demand. This may have been inadvertently due to the longstanding "innovation" theme and the generic character of BJET versus subject-specific journals such as, for example, the ones concerned with mathematics and science education or language learning with technology. It seems that innovation for BJET contributors included keeping up to date with new technologies emerging but at times taking for granted - or leaving aside for others to tackle - aspects like curriculum redesign.

The Bond et al. anniversary review considers each decade in turn, and extracts the key themes and emphases in the published articles. This makes fascinating reading and shows how the field has moved on exponentially. From the coinciding development of the Open University in 1971 and distance education as a research topic, we see a transition from audio-visual equipment to the design of computer-based learning in the 1980s, interactive multimedia, courseware and software development in the 1990s, the increasing appearance of collaborative, online and blended learning between 2000 and 2009. Over the last decade in particular, technology has become ever more adventurous. Papers published showed that it has offered broader and increased capacity for flexible design; for example, digital augmentation can be flexibly linked to interaction in terms of the different modes, contexts, timing, triggers etc. New interaction paradigms (embodied, enactive, experiential, sensory) are now emerging through the embedding and combining of technology with the physical world, and new communicative capacities are evolving.

However, over the past 50 years some themes have remained constant:

- Issues of novelty and technological development lead to challenges for undertaking longitudinal research that moves beyond novel 'engagement', and impacts on the effective embedding of technology into educational practice and contexts.

- Issues around initial teacher education and teacher professional development focused on effective uses of EdTech, the role of technology within and outside classroom settings, as well as structural, political and personal constraints.

- Issues of boundaries between school/training/work and home becoming increasingly blurred, as well as assumptions and expectations of (non-)access to and use of technology in schools and homes across socio-economic divides.

Related to the final point, the advent of "flipped learning", asking students to engage with EdTech and other resources outside of - and in preparation for - formal learning sessions, is a recent example of changing pedagogy. BJET has had a huge influx of articles on this popular topic. Two of the top 10 downloaded articles in 2017 focused on flipped learning and one of these, "A systematic review of research on the flipped learning method in engineering 
education" by Karabulut-Ilgu, Jaramillo and Jahren (vol. 49, issue 3), ranked in first place with over seven times as many downloads as its nearest rival.

Such an emphasis is beginning to address the earlier point about lack of curriculum development and course design. In recent years, technological development has facilitated and extended research that engages with learning beyond notions of individual factual knowledge and behavioural change, bringing new ways of realising approaches that engage more with the social, embodied, enactive aspects of learning and teaching. Digital tools can allow learners to explore the consequences of decisions, to experience a dangerous environment, and collaborate with people they will never meet face-to-face. At the same time, the technology itself can become a data collection instrument and learning analytics have emerged both as a methodology for understanding student learning processes and as tools to support practitioner awareness.

This is, of course, an upbeat perspective on the field and on the potential contribution that BJET can make to its further progress. In recent years, however, the current and previous Editors, Editorial Boards and reviewers have become concerned that many submissions focused on the digital tools themselves, often with a techno-evangelical outlook that avoided critique or proper evaluation. Empirical evidence was often weak and methods lacking in rigour. Studies frequently reported on learners' or teachers' attitudinal responses to - or "readiness" for adopting - a technological innovation or tool, without considering what learning it might support or how diverse the learners might be. Such studies are often quite parochial, as we have pointed out before; they may not offer messages for wider contexts. Moreover, theoretical underpinnings are also sometimes weak or almost absent. We caution strongly that the field's reputation is at stake here. Our team have continued the crackdown on such articles begun by our predecessors, and this has decreased the overall acceptance rate for BJET. Negative findings that make a contribution to the field are actively encouraged (as our 2018 editorial previously made clear) - not every intervention is successful and we need to share and learn lessons from the many failures. Likewise, BJET does not just publish empirical work and systematic reviews; theoretical/conceptual pieces are warmly welcomed if they are carefully researched and convincingly argued. Rigorously executed and well-theorised case studies are as welcome as large-scale studies reporting statistical analyses of significant differences, and the latter are only accepted when the differences are interpreted meaningfully.

We very much hope that the messages are getting through to authors now and that the proportion of substandard submissions is on the wane. Certainly it was encouraging to see that learning had the most direct mentions within the text of all themes emerging from the Bond et al. review, although obstacles to effective use of EdTech also emerged. Strong emphasis on critical and theoretical approaches to EdTech research, and on methodological rigour and diversity, were the focus of our lively and well-attended colloquium events held at the Open University in 2017 and 2018 in conjunction with the BERA Educational Technology Special Interest Group (SIG): the 2018 sessions were live streamed for viewers around the world (see link to video recording at https://www.bera.ac.uk/event/ed-tech-nov). We ask all our readers to continue to spread the word, especially to junior colleagues, so that collectively we can continue to raise the standard of work in this field. 
Other highlights in this first anniversary issue. Most of the articles in this issue are either looking back, reviewing a range of topics, or providing a good baseline for the start of the 50th year of BJET. Highlights include a review by Bodily, Leary \& West (2019) of scholarship and trends on instructional design and technology over the past decade. It demonstrates the diversity of this broad field but also makes a call for a less technocentric orientation and stronger influence of theoretical and design frameworks. Henritius, Löfström and Hannula (2019) review the research on emotions in studies on virtual learning. They summarise how these studies contribute overall to the field, pointing to a tendency to capture traits rather than the dynamic nature of emotional states, and focusing on the individual rather than group level processes. The third review paper by Daniel (2019) is addressing a contemporary topic - Big Data - and identifies a range of issues that educational researchers need to consider, putting a particular emphasis on big data as a research paradigm.

This last review of big data acts as a segue to three papers that look into the application of Learning Analytics for supporting self-regulated learning in flipped teacher education, for scaling the provision of personalised feedback and a framework and tools for learning design. The issue continues with a range of topical and timely papers from Massive Open Online Courses (MOOCs) to Augmented Reality and from science education to making.

Finally, we update our readership as usual on recent developments for BJET. First, although metrics have their known limitations, we are pleased that the impact factor continues to rise and is now 2.729 for 2017 (up from 2.41 in 2016), with a 5-year impact factor of 3.142. Significance of the work is of course paramount and we are also pleased that the rigour, influence and prestige of BJET came out rather highly in the independent analysis conducted by Bond et al.

Special issues/sections. To date BJET has published 21 special issues on a wide variety of subjects that were topical at the time (see the full list in Table 1 in the Bond et al., 2019, review). That number is set to increase significantly since we have introduced an annual open call for "Special Sections or Issues", and the response from the community has been tremendous, leaving us with some very difficult choices. We have expanded the number of such collections since although they can increase our workload and that of the editorial office, we feel that they offer a valuable service to the field in bringing together high quality research on cutting-edge topics, along with a guest editorial commenting on the trends emerging. Through this kind of snapshot of work in the field, we can see the state of the art and identify future directions. We will, in fact, publish more than one special section in some of the 50th anniversary issues, since so many high quality proposals were received in response to our special call for 2019.

Single-blind review system. The policy was reviewed by the International Advisory Board this year and overall considered advantageous to authors; it was thus retained. Not blinding author names and biographies enables the reviewers to offer support to early career researchers and those from low- and middle-income countries, where appropriate; it allows reviewers to detect links to and duplication of previous work; and it avoids authors having to expend time when preparing manuscripts in concealing identities that in this field are often recognisable anyway, given that technology and software systems described are often named. 


\section{Reaching forward}

As part of our 50th anniversary volume, we are looking forward to sharing with you a series of review articles which look back on the field, but also a series of special sections that help us reach ahead. As the editors of BJET we believe that these special collections provide an opportunity to take a significant step forward in our collective understanding. Given the trends over the past 50 years, it is perhaps unsurprising to see both formal and informal learning environments feature in the upcoming special sections, along with technology acceptance and adoption, lifelong learning and both personal and professional ecologies. Following the aforementioned BERA EdTech SIG / BJET events at the Open University, we particularly look forward to the special section on critical and theoretical approaches to research in educational technology to be published in one of the 2019 issues.

There is one remaining open call for papers on "human learning and learning analytics in the age of artificial intelligence' and on behalf of the guest editors, we would like to encourage anyone who is considering submitting. The submission deadline is 10th February 2019 and selected papers will appear in the final issue of Volume 50 in November 2019. For more information, please visit the BJET website (https://onlinelibrary.wiley.com/journal/14678535).

What are the desirable future directions for the future of the field of EdTech and for BJET, not just throughout 2019 but into the 2020s? The Bond et al. and Bodily et al. reviews and the discussion above indicate that there is ample scope for more emphasis on theory, design frameworks, critical perspectives, honest reports of less-than-perfect technology implementations, and more thinkpieces. Some of the substantive hot topics have been outlined above too. It is important that potential authors take note of these reviews in framing their own studies and articles; we often have to turn articles down because they appear to make little original contribution to the field and fail to move our knowledge or thinking forward. This expends a lot of time and energy unnecessarily, for authors, reviewers and ourselves. Please avoid reinventing the wheel!

One emerging area of interest is around immersive technologies, and their use /role in teaching and learning. While current VR (virtual reality) technologies raise some important ethical issues and consideration, especially in early years settings and long-term use, other important topics for education include various contexts of use, such as science laboratories, where handling real chemicals may be dangerous; instructional design behind VR experiences; relevant theoretical approaches, e.g. embodied cognition and interaction, multimodal and multi-sensory approaches; levels of immersion for effective learning; embodied interactions afforded by the technology. We expect to receive an increasing number of articles on immersive technologies. Again we hope that the novelty of these sophisticated tools will not occlude the all-important emphasis on learning.

Research contexts. The Bond et al. review indicates that BJET has had an almost equal focus on schooling as on higher education over its history, with a smaller but still substantial focus on training and professional development. BJET articles are increasingly co-authored as the review points out, and pleasingly, many teams and the studies they report are crossdisciplinary. However educational technology is of course important in other sectors 
including informal and community education, and we welcome more submissions from these sectors.

Impact on and implications for practice have long been stressed in BJET articles, and the Practitioner Notes are an established mechanism. However two major gaps detected are (a) work related to educational policy and (b) the voice of practitioners. Systematic reviews are one way of addressing a lack of evidence-based policy making, and linking the outcomes of these and other published articles to blog posts could potentially engage both policymakers and practitioners more readily than attempts to disseminate journal articles themselves. Some BJET authors are taking up our invitations to publicise their work via a post in the BERA blog which is widely read, but there is scope - and encouragement from the blog editorial team - for far more of them. Let's get the work out there in an accessible format!

Although BJET is an academic journal and it may be unrealistic to expect practitioners who often lack access to academic sources and training in research methodology to submit more articles, there are other ways of addressing the second gap. We strongly endorse the Bond et al. review's recommendations that closer relationships of practitioners with instructional design teams could be beneficial and that academic researchers should consider involving educators in more inquiry research, data analysis and the academic writing process. Some of our own research takes precisely that approach and we very much hope that it will become more widespread in the field. The BJET community may like to identify and share further strategies.

Further developments on the horizon are in keeping with our three guiding themes and include consideration of how to

1. increase engagement with authors in underrepresented regions, such as Africa, the Middle East and South America (internationalisation);

2. support more doctoral students and early career researchers in getting published in BJET (inclusiveness);

On these two points, we are very pleased indeed that BJET authors over the past 50 years have come from at least 72 different countries, across six continents, and that the proportion of UK authors has dropped dramatically over that period, from almost $70 \%$ in the 1970 s to under $20 \%$ now (Bond et al., 2019, Figure 9). The retention of the term "British" in the journal title has been questioned by some, however BJET has a strong reputation - and increasing submissions from - across the world so there seems little motivation to change the title now. It is of course edited mainly by British researchers too, and associated with the British Educational Research Association. Measures have been take to support early career researchers, as Bond et al. acknowledge. Analysis shows that over the last 3 years, $18 \%$ articles accepted have submitting authors without a doctorate; most of these authors are likely to be research-inexperienced if not actually "early career". Nevertheless, on both fronts there is room for development. We call for assistance from experienced scholars in the field, in particular to come forward as critical friends who can mentor less experienced colleagues and those from low- and middle-income countries (who may be disadvantaged by lack of access to research literature). Please contact our editorial office (bjeteditor@wiley.com) if you can help. 
3. engage with the shift towards open research that is very rapidly gaining momentum now (innovation).

On this final point, we welcome suggestions or feedback based on your experience so far on topics such as challenges and opportunities of open access and particularly publicly funded research, open sharing of data, software or other tools or services and pre-registration of studies in order to reduce positive results publication bias. These approaches are under ongoing discussion between ourselves, our International Advisory Board, BERA and our publisher Wiley. Watch this space!

We conclude by wishing all our readers, Board members, authors and reviewers a Very Happy New Year.

\section{References}

Bodily, R., Leary, H. \& West, R. (2019). Research trends in instructional design and technology journals. British Journal of Educational Technology, 50 (1).

Bond, M., Zawacki-Richter, O. \& Nichols, M. Revisiting five decades of educational technology research: A content and authorship analysis of the British Journal of Educational Technology. British Journal of Educational Technology, 50 (1).

Daniel, B. (2019). Big Data and data science: A critical review of issues for educational research. British Journal of Educational Technology, 50 (1).

Henritius, E., Löfström, E. and Hannula, M. (2019). University students' emotions in virtual learning: A review of empirical research in the 21 st century. British Journal of Educational Technology, 50 (1). 